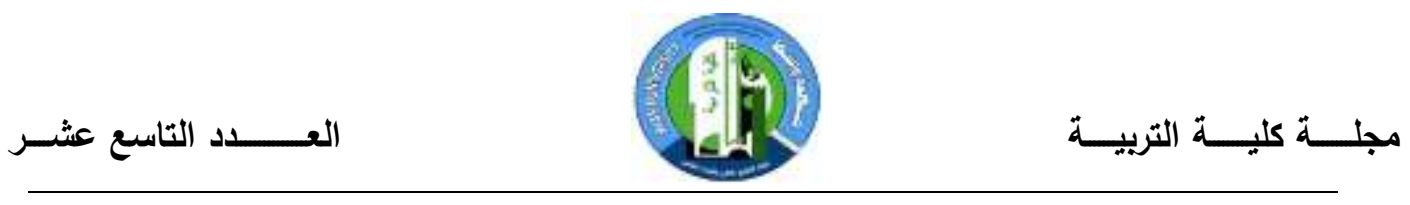

\title{
البحث في اخطاء طلبة الجامعات العرقية متعلمي اللغة الانكليزية بوصفها لغة اجنبية في استعمال التعابير الاثارية في مسرحية هاملت لثكسبير
}

م .إيلاف صبحي عبدالله

جامعة تكريت/كلية التربية للبنات

\begin{abstract}
$\underline{\text { Abstract }}$
Deixis is a specific kind of reference in that it is more dependent on the situation. There are five kinds of deixis: personal, temporal, spatial, social and discourse. Throughout working as a lecturer in the university, the researcher has found that many Iraqi students have difficulties in determining the deixis and its kinds and how they function in language. So, this study aims at searching the difficulties and investigating the errors of Iraqi EFL learners in determining the deictic expressions. This study investigates specifically these deictic expressions in drama and the researcher has chosen $4^{\text {th }}$ year students to test their difficulties in these expressions in the play of Shakespeare's Hamlet since this play includes many deictic expressions in that it can reflect clearly the difficulties of the students. Besides, the students have read and studied this play in the third year. It is hoped that this study can help the teachers in drama as well as those specialists in EFL to identify the difficulties of students and at the same time the students can understand this play clearly by using deixis and give them an idea about how the theme of the play can be understood more clearly through the use of deixis.
\end{abstract}




\section{الملخص}

تعد الاشاريات نوع خاص من الاشارة والذي يعتمد كثيرا على الحالة. هناك خمسة انواع من الاشاريات : الثخصية ، والزمانية والمكانية والاجتماعية ، والخطاب .وجدت الباحثة من خلال عملها بوصفها استاذة جامعية ان العديد من الطلبة العراقيين لديهر صعوبات في تحديد الاثاريات وانواعها وكيفية عملها في اللغة. لذلك ، تهدف هذه الدراسة الى البحث عن الصعوبات والتحقيق في اخطاء الطلبة العراقيين متعلمي اللغة الانكليزية بوصفها لغة اجنبية ـ تبحث هذه الدراسة بشكل خاص هذه التعابير الاثارية في المسرحية وقد اختارت الباحثة طلبة المرحلة الرابعة في اختبار صعوباتهم في هذه التعابير في مسرحية هاملت لثكسبير وذلك لان هذه المسرحية تحتوي على العديد

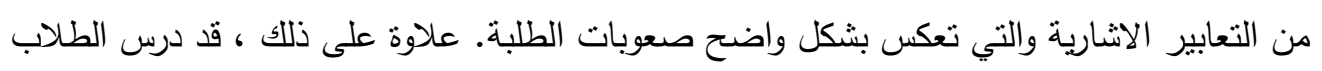
هذه المسرحية في المرحلة الثالثة . ومن المؤمل ان هذه الدراسة تستطيع ان تساعد مدرسي المسرحية بالاضافة الى المتخصصين في تعلم اللغة الانكليزية كلغة اجنبية الى التعرف على صعوبات الطلبة وفي الوقت نفسه بامكان الطلبة فهم هذا المسرحية بشكل واضح باستعمال الاشاريات وتعطيهم فكرة عن كيفية فهم موضوع المسرحية بشكل واضح من خلال استخدام الاشاريات. 


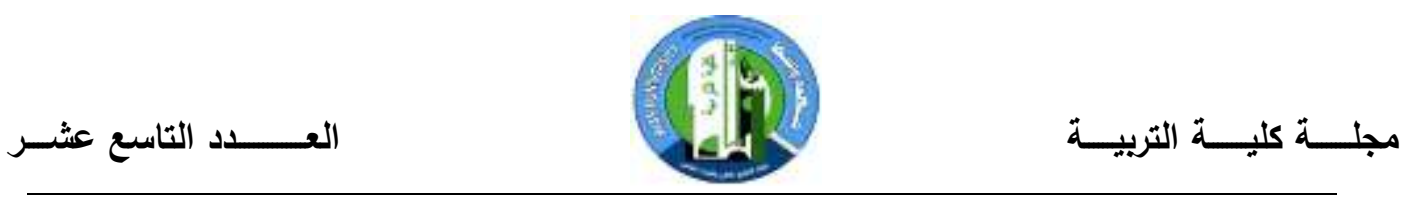

\section{Section One}

\section{Introduction}

\subsection{The Problem of the Study:}

Deixis, as an expression, means to point and as a linguistic category, it means situational reference. Deixis is regarded as one of the most major things the people do with utterances. The researcher has found that many college students have difficulties in determining the deixis with its kinds and how it functions in language. So, the researcher tries to investigate the errors that the students have made in this area of linguistics especially when it is used in literary text.

\subsection{Aims of the Study:}

It aims at:

1- Presenting an acceptable interpretation of the deictic expressions.

2- Presenting a clear and comprehensive account of deixis with its components.

3- Investigating and identifying the errors of the students that have faced in using deictic expressions and their types.

\subsection{The Hypotheses:}

It is hypothesized that :

1- Drama is a main context for deixis.

2- It is significantly that the students, to such an extent can recognize the explicit deictic expressions and they encounter more difficulties in recognizing the implicit ones.

3- There is no statistical significance difference among Iraqi college students in using deictic expressions in drama especially in the play "Hamlet". 


\subsection{Limits of the Study:}

1- The study is limited to the fourth year students of English department , at College of Education for Women - University of Tikrit for the academic year (2012-2013).

2- It is concerned with the investigation of college students' errors in using deictic expressions in the play of Shakespear's "Hamlet".

\subsection{Procedures of the Study:}

1- Presenting a theoretical background to deixis and some other related terms.

2- In order to achieve the aim of this study, the researcher has chosen $4^{\text {th }}$-year students to test their difficulties and errors in these expressions in Shakespear's Hamlet play since it is taught in the previous stage and it includes many deictic expressions.

3- This study can help to measure the difficulties and at the same time the students can understand this play clearly by using deixis.

4- Analyzing the results of the test in order to indicate the answers of the students and to prove the hypotheses of the study.

5- Drawing a number of conclusions.

\subsection{Value of the Study:}

This study is hoped to be valuable to researchers of linguistics specifically those who specialists in EFL since it is concerned with the investigation of the difficulties of EFL learners and one of the objective sources of information, i.e. deixis. Also, it is useful for linguists, language teachers and students of English language. 


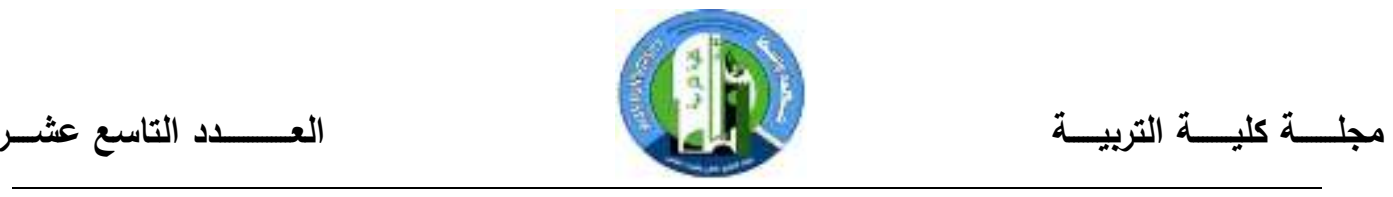

2- The Concept of Deixis

\subsection{Definitions of Deixis}

There are some expressions in the language, such as: I, you, her, now, yesterday that cannot be construed perfectly unless the physical context of the speaker is known. These expressions are called deixis or deictic expressions.

Deixis has been defined by Fillmore(1982:35) who states that it is" the name given to uses, items and categories of lexicon and grammar that are controlled by certain details of the inter locational situation in which the utterances are produced . In addition , Levinson (1983:45) indicates that " the clear way in which the relation between language and context is reflected in the structures of languages themselves is by the phenomenon of deixis".

Hurford and others (1983:66) mention that a deictic word is a word which conveys its meaning from the context or situation (i.e. the speaker, the addressee, the time and the place) of the utterance in which it is used. For example :- the first person singular pronoun "I" is deictic. When Ben Heasley says I've lost the contract, the word I here refers to Ben Heasley.

Besides, tenses which indicated past, present and future time can be also regarded as deictic, because these times are defined by reference to the time of utterance (Ibid:67).

Yule(1996:9) says that deixis is " a technical term for one of the most basic things we do with utterances ". It means pointing via language. All linguistic forms used to point at

Crystal (2003:127) defines deixis as " a term used in linguistic theory to subsume those features of language which refer directly to the personal temporal or locational characteristics of the situation within which an utterance takes place, whose meaning is thus relative to that situation".

Finally, the researcher has been agreed with Crystal 's definition of deixis because it is general and deals with the types of deixis. Also, it has concentrated on the situation of utterance of the speaker which is very important for deixis.

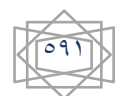


2.2 The Pragmatic Nature of Deixis:

Deictic expressions require contextual information which involves knowledge of the identity of the speaker, hearer and other participants. For example:

1. I played here yesterday.

There are three deictic words in this sentence, I ; the actual referent depends on who uttered the sentence. Here; the actual location depends on where the sentence was uttered. Yesterday; the actual time depends on when the sentence was uttered.

2. Meet me here at noon tomorrow with a stick about this big.

Fillmore indicates this sentence by saying a bottle is found floating in the ocean and containing this note, we do not know who to meet, where and when to meet him or her or how big a stick to bring.

3- You will have to bring that back tomorrow, because they are not here now.

Unless we identify the persons referred to by you and they, the place denoted by here, the time specified by tomorrow and now, we can not consider this sentence correctly. So, these sentences are vague and out of context.

(Fillmore, 1997:60)

In addition, there are four dimensions of context that are encoded through deictic expressions like speaker, hearer, time and place. Therefore, context is very essential. It plays an important role for the construing of deictic or situational reference item without it they cannot convey meaning. So, a deictic expression is one whose referent is determined by the speech context. Levinson (1983:24) states that " at least the one that focuses on the nature of context makes it clear that one of the goals of a pragmatic theory should be to explicate that nature".

Deixis, which concerns the relationship between the structure of languages and the context of situation, falls within domain of pragmatics. 
2.3 Symbols Deixis and Gestural Deixis :

Symbolic deixis refers to a deictic expression whose construing does not necessarily depend on the physical circumstances, but their knowledge of certain aspects of speech communication, e.g.,

4- Is Jane there?

In this sentence, there does not require the hearer to know where exactly the speaker is referring to; therefore, there is no need to point to somewhere. The hearer understands that there refers to the room, home, town depending on the context where the hearer is located (Fillmore,1997:63).

The pointing of finger, hand movements, and glances belong to deictic expressions ( Frege,1967:24).

Faerch (1975:326) indicates that the speaker can use deictic gestures either by pointing at the objects and uttering the expressions, e.g.,

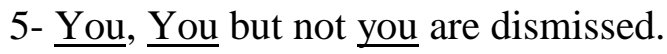

6- This finger hurts me.

Or, just by pointing. Gestures are not equivalent to speech, but gestures and speech complete each other, for example:

7- Put it over there.

The hearer cannot construe what there refers to, when he cannot see where the speaker is pointing to. So, we can say that gestures describe the basic meaning of the deictic expression.

Pointing is one method of identification by bodily gestures on the part of the speaker. So, personal and demonstrative pronouns are clearly deictic expressions (Levinson,1983:60). For example instead of saying; I am sad, a speaker can point to himself and say; sad instead of saying; that is beautiful, a speaker can point to a particular painting at an exhibition and say beautiful (Lyons, 1981:229). 
2.4 Deixis and Reference:

Kempson (1975:31) indicates that the relationship that holds between the abstract symbols of language (words) and the external world (things) is the relationship of reference.

Halliday and Hassan (1976:32) differentiate between two types of reference; situational (exophoric reference) and textual (endophoric reference).

Exophoric reference signals that the referent must be in the contextdependence without the context we cannot construe what is said. While, Endophoric reference signals that the information found in the text itself. The referent item is derived from the text falls into two kinds (anaphoric) or the following one (cataphoric).

Also, they state that reference to the situation is the prior form of reference, while reference within the text is a secondary or derived form of this relation. In the evolution of language, situational reference precedes text reference since, it is easier to refer to things in face - to - face than to refer to things mentioned in the text.

Deixis does not necessarily include reference because deictic expressions do not name anything but they point to someone or something. They just signal that reference must be made to the context of situation, like; John, tree, cat have referential meaning since they are names for person or objects.

Deixis is like reference because it participates in the creation of text; it links language with the context of occurrence. But it does not participate directly in the cohesion since it does not bind the two elements together into a text (ibid:36-37).

So, Lyons (1981:168) defines reference from a semantic view as a relation which holds between the linguistic elements (pronoun, demonstrative or comparative) and the non-linguistic world of experience (entities, properties or situations in the outside world).

Also, Lyons (1985:170) states that deixis and reference are two overlapping phenomena, but deixis is both wider and more limited than 
reference. Deixis is wider because reference may or may not be deictic. On the other hand, deixis is more limited because deixis doesn't necessarily involve reference.

According to this discussion, deixis is considered as a pragmatic category, while reference is a semantic one.

\subsection{Types of Deictic Forms:}

There are several types of deictic forms can be summarized as follows:

\subsubsection{Person deixis:}

The role of the speaker in person deixis is changing to that of the hearer and vice versa. Verschueren (1999:20) defines person deixis as the most basic dimension of deixis. "face-to-face conversational context" contains the three roles in addition to others present in the context. The use of these roles has its own specific features. Conversation usually employs the three roles with one talking and other listening. So, person deixis can be classified into the following types:

\subsubsection{Pronouns}

Pronouns are referring expressions, they refer to persons and things in language, they are syntactically equivalent to nominal (Lyons,1977:637) as shown bellow:

8- (a) The boy killed the rat,

both nouns in the sentence can be substituted by the pronouns he and it respectively. So, he and it stand for the nouns the boy and the rat. The sentence will become:

(b) He killed it.

In this sentence, the meaning changes from one utterance context to another. It gets its meaning from the utterance context, i.e., without knowing who the hearer is, we have no idea what the referents of he and it are. So, we 
can say he, it and other personal pronouns get their meaning directly from utterance context (ibid.)

Pronouns like: you , your, I , my, he, his can be deictic. These pronouns make sense if be able to identify their referent. So, the most common examples of person deixis are the three personal pronouns: first, second and third person pronouns (Yule,1996:10).

Table (1) Forms of person Deixis

\begin{tabular}{|c|c|c|}
\hline Person & Singular & Plural \\
\hline $1^{\text {st }}$ person pronoun & I & We \\
\hline $2^{\text {nd }}$ person pronoun & You & You \\
\hline $3^{\text {rd }}$ person pronoun & $\mathrm{He} / \mathrm{she} /$ it & They \\
\hline
\end{tabular}

For example: the person pronoun I takes its meaning from situation (the speaker) of the utterance in which it is used. Hurford and Heasley (1983:63) show that by saying ; "when Ben Heasley says; I've lost the contract, the word I here refers to Ben Heasley. When Penny Carter says; I'll send you another one, the I here refers to Penny Carter".

\subsubsection{Proper Names:}

Like Jack, Mr. Brown, etc. It should be able to clarify the person called "Jack" to interpret the meaning of the utterance in which this name is used.

Yule and Brown (1983:210) state that proper names identify persons specifically and appear in certain type of situations and not in all of them. So, a proper name such as Marry is used to point to one particular individual in a particular situation in spite of the fact that there are many Marrys other than the intended one. Also, proper name is used to denote something other than the person named as in the following example:

9- Plato is on the bottom shelf of the book case. 
In this example the name refers obviously to a book rather than the philosopher himself. The determination of referents is done according to the predicate of the sentence "bottom shelf". The use of proper names may be done variantly in different situations in accordance with the roles taken by the persons referred to.

\subsubsection{Demonstrative Adjectives and Pronouns:}

For example: this, this man, that woman, those men, etc. These words are used as deictic expressions.

Generally, person deictic includes information of different kinds concerning the identification of the speaker and addressee of the individuals represented by the referents, the social, and personal relations. So, first person, for example, is the participation of the speaker, temporal and spatial deixis are organized around the location of the speaker at the time of speaking. Thus, the first is speaker inclusion and second person is addressee inclusion.

Such as:

10- I will meet you tomorrow. (Hurford and Heasley, 1983:66)

Third person pronoun is unlike first or second person because it does not correspond to any specific participant role in the speech event (Lyons,1977:638). First and second persons are considered as the positive members of person deixis, while the third persons are considered as negative members of person deixis.

Besides, Levinson (1983:71) says that there are other forms to be included within person deictic as those which have implicit first person possessive features as "my mother's brother". Also, vocatives are considered as part of person deixis, it can be classified into two categories: summonses as in (11) and addresses as in (12).

11- Hey you, you just scratched my car with your Frisbee.

12- The truth, madam, nothing is as good nowadays. 

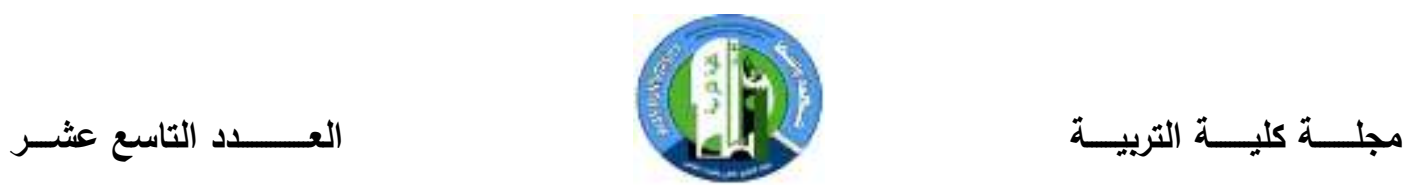

Person deixis has a special importance because of its omnipresence, it is a grammatical category marked or implicit in every utterance which is indicated by first, second and third person.

\subsubsection{Time Deixis:}

Time deixis is a complex type since it contains the coordination of deictic concepts with non-deictic equivalents. Time deixis likes other deictic types is related to person deixis. The time of producing the utterance should be distinguished from the time of receiving it. (Levinson,1983:73)

Jespersen (1924:313) defines mood as is a grammatical category related to the inflectional form of verbs which is exploited in languages to express attitudes of the mind of the speaker towards the content of the sentence. For example:

\section{3- I will write as soon as I can.}

Time deixis is grammaticalized mainly in the tense system of the particular language. Jesperson (1931:1) defines tense as a deictic category which expresses the temporal relationship between the event described by the verb and actual utterance. Tense is considered as a property of the sentence and the utterance whose function is to relate the time of the event in the sentence to the time of utterance. So, tense system is deictic because it locates events in the present or past. In addition, modality is sometimes used to include mood and it may be expressed by prosodic and paralinguistic features such as stress or gestures. Therefore, deixis is in fact part of modality function of language.

Halliday (1976:205) indicates that both tense and modality are deictic but they differ only in the type of deixis included; i.e., at the time of speaking or in the opinion. Modality deals with judgments which are grammaticalized through the use of modal auxiliaries and it expressed by the judgments that includes certainty, possibility, ability, permission, intention and obligation. 


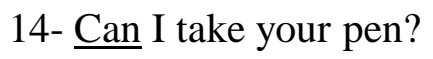

15- They may go tomorrow.

16- You must work hard.

There is a relationship between future time and modality since future can be used to express supposition, intention, inference, permission, wish (Lyons, 1977:816).

Morphologically, English has no future form of the verb in addition to present and past forms, most grammarians state that English has only two basic forms of tense; present and past. The tense of the following sentences are present and past respectively.

17. (a) He plays football here now.

(b) He played football there then.

In the present tense the action takes place at the same time of the utterance, while in the past tense, the action takes place prior to the utterance point. So, the proximal form is the present tense and the distal form is the past tense.

The proximal form 'now' can be indicated as the time of the speaker's utterance and the time of the speaker's voice being heard, as in (18) I write now. Also, the distal expression 'then' can be used as both past (19.a) and future (19.b) time related to the speaker's present time.

19. a. November $25^{\text {nd }}, 1993$ ? I was in England then.

b. Dinner at 9 o'clock on Monday? Okay, I'll see you then.

(Yule,1996:14)

There are some systems of non-deictic temporal reference such as : Calendar time (date, as in 19.a) or clock time (hours, as in 19.b). So, these forms of temporal reference can be learned a lot than the deictic expressions like 'yesterday, tomorrow, today, tonight, next week, last week, this week....etc. 
All these expressions depend for their interpretation on knowing the relevant utterance time.

(ibid)

Temporal events can be treated as objects that move toward us or a way from us. In English, the events which are coming toward the speaker from the future (ex:- "the coming week', the approaching year') and going away from the speaker to the past (ex:- in days gone by', 'the past week'). Also, the near or immediate future can be treated as being close to utterance time by using the proximal deictic 'this', as in 'this coming weekend' or 'this coming Thursday'.

(Yule, 1996:14)

\subsubsection{Place Deixis:}

The concept of distance is clearly related to place deixis, where the place of people and things is illustrated. Locating things in space relative to the speaker and the hearer is more complicated than those of time. This is because the speaker and hearer are assumed to be in the same point in time, they are not necessarily be in the same place at the time of speaking (Dilllon,1977:102-3).

The spatial demonstratives and adverbs have contrastive spatial functions, for instance 'this' and 'here' refer to objects or locations proximal to the speaker. On the other hand 'that' and 'there' are referring to objects and locations distant from the speaker (Wales, 1979:242).

There are many prepositions such as: by, over, under, above, below, behind and in front of can be used in a static sense of orientation, indicating a point where in reality or imagination the speaker standing (Quirk et al., 1973:151).

20- He lives across the moors.

21- The car is behind the bus.

Place deixis may be represented by certain concepts which are relative both to the speaker and the hearer, such as 'come', 'go', 'bring' and, 'take' which are explained by the accompanying text in which they occur. There are three distinct purposes for which the directional verbs; come, go, take and bring are 
used. First, hearer movement toward the speaker as in come here, go there. Second, speaker movement toward the hearer as in, I'll come over there at six o'clock. Third, 'come' is used in past speaker movement toward his present place as in, I came here after the movie. The verb " go" is used in past speaker movement toward the place in which he is not present as in, I came there after the movie. And fourth, 'come' is used in future speaker movement toward the place whether he is not present as in:

22- I'll go there after the movie.

(Louise and Closs, 1980:275-6)

Point of orientation shows deictic features of meaning similar to that of the demonstrative use of this and that in these phrases.

23- This side of the box.

24- This side of the tree. (Levinson,1983:82)

In the first sentence this side means the surface of the box that can be called a side which is nearest to the location of the time of utterance, while in the second sentence means area of the tree visible from the point where the speaker is at the time of utterance.

\subsubsection{Social Deixis:}

Language is part of socio-cultural behavior. So, it is both governed by social rules, and at the same time it reflects the way a given community or society works. In this sense language as a system of classification and categorization reveals the kinds of mental representations that are encoded linguistically in different societies (Downing, 2000:1).

Social deixis has to do with the marking of social relationships in linguistic expressions, with direct or oblique reference to the social status or role of participants in the speech event.

Levinson (1983:89) defines social deixis as: 


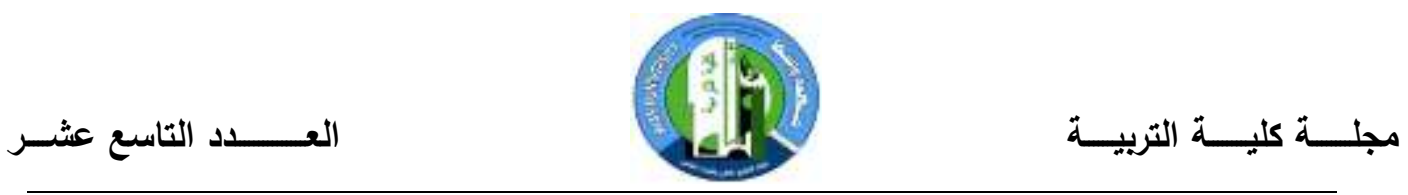

That aspect of sentences which reflect or established or are determined by certain realities of the social situation in which the speech act occurs.

An important portion of language depends on the relationships between the interlocutors. An employment of such relationships appears in polite pronouns and titles of address. So, he (ibid:90) says that there are two basic kinds of social deictic information that seem to be encoded in languages around the world. These are relational and absolute social deixis. The relational variety is the most important, it falls into four sub types, according to the other partner who shares the speaker. These types are held between the speaker and the referent, the speaker and the addressee, the speaker and the bystander(s), and the speaker and the setting.

While, the other kind of social deixis is absolute social deixis which is deictic reference to some social characteristics of a referent apart from any relative ranking of referents. So, the form of address will include no comparison of the ranking of the speaker and hearer. There will be only a simple reference to the absolute status of the hearer, e.g. Mr. president, you're honor (Levinson, 1983:91).

In general speaking, social deixis applies to the ways in which speakers can reflect their own social status or the status of the hearer or even the status of non-participants when they are talking about as well as ways of reflecting social relations in general.

Lyons (1983:280) subsumes honorific distinctions within social deixis because these distinctions are more relative to social ranks than to participant roles. Manifestations of these distinctions are found in European languages such as (French, German, Russian, Latin, etc.)

Honorifics are socially deictic, as they are indicators of the relationship between participants. If they do not know each other, or the status of the speaker is trying to show respect for the hearer, a polite form of the personal pronoun is required (Calude,2002:3). For example; the use of the first person plural rather than the first person singular expresses majesty since the ruler speaks of himself in his official announcement by using the first person plural we rather than the first person singular I, and for this reason we is called the royal pronoun (Abbas, 1980:29).

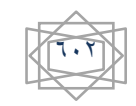


So, the pronoun we can be used to refer to the singular when the speaker has a certain high social status, it is used by president, kings, lords, etc. For example; A president or king may say; we decree instead of I decree.

Persons make distinctions between the social status of the speaker and hearer. The higher, older, and more powerful speaker will tend to use familiar version to a lower, younger, and less powerful hearer and be addressed by the non-familiar form in return participants are either of equal social status or not and, if they are of unequal status, one of them will be the superior and the other is inferior. Social superiority depends upon social status; i.e., parents being superior to sons, teachers being superior to pupils, and an older person to a young person and so on (Lyons, 1977:641).

\subsubsection{Discourse Deixis:}

Levinson ( 1983: 85-6) indicates that 'this' and 'that' can be used as discourse deictics, this refers to a following piece of discourse as in ( 25 ) and that to a previous piece as in ( 26 ).

25- I bet I haven't heard this story.

26- That was the funniest story I've ever heard.

Yule and Brown (1983:59) illustrate that discourse deixis can be represented by many words and phrases which indicate a connection between the expression and a previous discourse like: but, all, therefore, in conclusion, to the contrary, still, however, anyway, well, besides and so on.

Verschueren (1999:21) states that discourse deixis is any indicating or pointing to a previous, present, or later piece of discourse. "reflexive or self referential discourse deixis is referring to the present or current piece of discourse as in the following expressions; this book, this section, his voice is like this when making a sound like some ones else. A "projective discourse" is mostly employed in which the speaker is narrating events as when one says I'll tell you the whole situation. A piece of discourse may be " projective and reflexive" at the same time as in "this book will explain.....".

In addition, crystal (2003:96) states that discourse or text deixis is used for words which refer forwards or backwards in discourse. Discourse deixis ,unlike to the other deictic types, is not related to the context of situation but to the discourse itself.

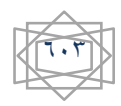




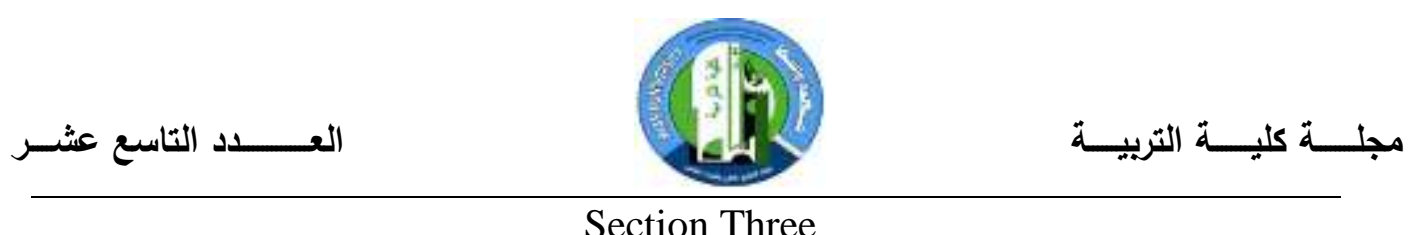

Section Three

Procedures of the Study

\subsection{Introduction :}

This section intends to test the hypotheses which concerned with how the college students make many errors in comprehending and using deictic expressions especially in literary text. So, deixis is a technical expression for one of the most basic things we do with utterances, it means pointing via language.

Besides, this section contains the practical procedure of the study which involves: the sample selection, test construction, the scoring scheme, test validity, test reliability, test administration and statistical means.

\subsection{The Sample Selection:}

The sample in this study is the fourth stage students of English department at College of Education for women in the academic year 20122013.

The sample consists of (25) students. The researcher has chosen the sample of the students randomly.

\subsection{Test Construction:}

In order to measure and evaluate the students' achievement, an achievement test has been constructed. Therefore, this test will be the instrument of measurement. As Baker (1989:3) indicates that "a test is away of arriving at a meaningful decision."

The test consists of two questions. The first question consists of (8) items, these items contain (20) deictic words and phrases with their types which have been distributed randomly on these items. Both questions of the test are concerned with different types of deictic expressions which have been taken from the play of "Hamlet". 
While question two consists of (3) items, these items contain (10) blanks including deleted deictic words and phrases. So, the students should have to complete these blanks with the correct use of these kinds of words.

Therefore, the first question is recognition because the students should have to recognize and indicate the deictic word or phrase with its type. While the second question is production, because the students should have completed the spaces with the suitable deictic word or phrase from their own words or their knowledge of the subject.

All these items are mostly familiar to the students, as they have already studied in the previous year when they are in the third stage in their text book of the play of Shakespear's "Hamlet".

\subsection{The Scoring Scheme:}

The responses of the students have been corrected by the researcher herself, they are either correct or incorrect. The test has divided into two questions. The first question has taken (40) scores. It contains (20) words and phrases about deictic expressions with their types. When the testee has chosen the correct word or phrase and identified its type, this answer has taken (2) marks (i.e. correct response). But, when the response is incorrect, the word or phrase with its type has scored zero. There are no biased scores. When a word or phrase is left (i.e. the testee has not used it in the test), it is counted incorrect and it is scored zero. While, the second question has taken (10) scores. When the testee has completed the blank with the correct word or phrase, this answer has taken (1) mark. And the incorrect response has taken zero mark. So, the total marks of the test are (50).

\subsection{The Pilot Study:}

To discover the difficulties in the test, a pilot study is conducted to achieve the following:

1- Estimate the time needed for the final administration of the test.

2- Have an idea about the requirements and arrangements for the final administration of the test.

3- Find out the reliability of the test. 
This study has been applied on (25) students from fourth stage at College of Education for women, University of Tikrit, and are assigned to be members of the pilot study. These students are asked to answer the questions of the test after telling them its purpose. After giving the students some instructions about the test, they are encouraged to ask for any clarification if needed. For this reason some items are modified and others are clarified. The time is needed to achieve this task is about fifty minutes. The pilot study has clarified that some difficult items are detected or modified, whereas others are understandable to the students.

\subsection{Test Validity:}

There are two important characteristics in the present study, test validity and reliability.

Harrison (1983:11) defines the validity of the test as "the extent to which the test measures what it is intended to measure". Validity has many different types, the most important are face validity and content validity. Face validity is emphasized on what teachers and students think of the test. In order to achieve face validity is to expose the test to a jury of experts. While content validity is concerned with the objective of the course taught.

Therefore, the test is given to the jury of experts in English department. They are asked to study the test to add, modify, or change anything they consider necessary. So, many suggestions and indications have been made by the jury on the test, which are taken into consideration. All the members have agreed the test is suitable and correct for assessing the students' achievement in indicating and using the deictic expressions in the correct way. 


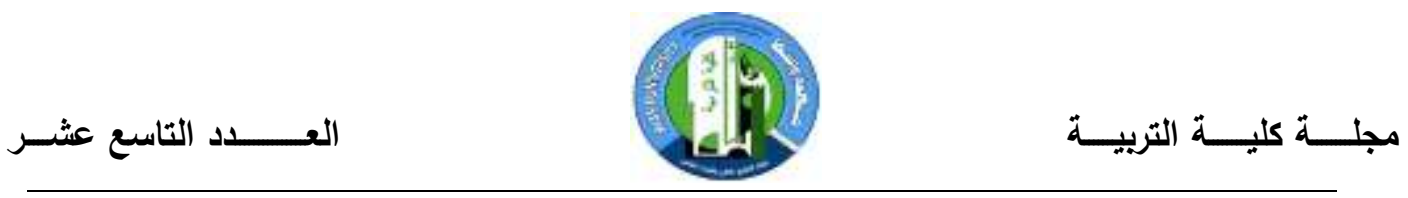

The jury of experts are as follows:

1- Dr. Madeha S. Salah

2- Dr. Ali T. Al-Jaboori

3- M.A. Zaineb A. Ali

4- M.A. Hanan K. Omer Instructor/ College of Education for

Women / University of Tikrit.
Assist. Prof. College of Education for

Women / University of Tikrit. Assist. Prof. College of Education for

Women / University of Tikrit. Instructor College of Arts/

University of Tikrit.

5- M.A. Abdalmonaam K. Ali Assist. Instr./ College of Education for Women / University of Tikrit.

\subsection{Test Reliability:}

Harrison (1983:11) defines reliability as "the consistency with which a test measures the same thing all the time". So, reliability includes three aspects: the place in which the test is produced, the way in which it is marked and the unity of the assessment it makes.

Therefore, reliability can be measured by a correlation between the scores of the same group of students on two administrations of the test. This is called the re-testing coefficient of reliability. (Lado,1961:31)

Heaton (1975:156) indicates that when the correlation between the two tests is high (i.e. when the grades that obtained from the two tests correspond closely to each other), then the tests can be called reliable.

So, the researcher has used in this study the test-retest way. Twenty five students of the fourth stage are selected. They are re- examined after twenty-one days of the first administration. The test papers are examined and 
the Pearson Correlation Coefficient formula has been used between the scores of the students. The result of calculating correlation coefficient of reliability is $(0.90)$. So, the test is highly reliable.

\subsection{Test Administration :}

The researcher has explained initially the objectives of the test to the students, who has distributed the sheets of the test to the testees.

Therefore, the test has been administrated on (25) students in English department, College of Education for Women at University of Tikrit. The test is given to them at the end of the second course of the academic year 20122013.

The test papers are printed in order to be as interesting as possible. So, the questions of the test has been printed on one side of the paper. For practicality, the test paper is used as an answer sheet. After that the researcher has collected the test papers by herself and the responses of the students have been checked, corrected and analyzed by the researcher. 


\subsection{Statistical Methods:}

In order to achieve the purposes of the test, the researcher has been used variety of statistical methods as follows:

1- Percentage: this method is used to estimate the percentage of errors (i.e. incorrect responses) for each deictic word or phrase in the item of the questions of the test.

2- The pearson formula for Correlation coefficient is used to measure the reliability of the test.

$$
r=\frac{N \sum X Y-\left(\sum X\right)\left(\sum Y\right)}{\sqrt{\left[N \sum X^{2}-\left(\sum X\right)^{2}\right]\left[N \sum Y^{2}-\left(\sum Y\right)^{2}\right]}}
$$

(Bruning and Kintz,1968:153)

3-T-Test for paired samples:

This method is used to measure and count the difference between the results of the group of the students in the same test, but in different time. Also, it is used to make a comparison between these different results in their achievements (i.e. in the way of answering the items of the test). So, this formula has been indicated as follows:

$$
t=\frac{\frac{\sum d}{N}}{\frac{\sqrt{\sum d^{2}-\frac{\left(\sum d\right)^{2}}{N}}}{N(N-1)}}
$$

$\mathrm{d}=$ difference between matched scores.

$\mathrm{N}=$ number of pairs of scores.

(Ibid.:154) 
4-The mean score is used. Heaton (1975:169) indicates the mean score as "the arithmetical average: i.e. the sum of the separate scores are divided by the total number of testees .... The mean is the most efficient measure of central tendency." The following formula is used : $\bar{X}=\frac{\sum X}{N}$

5-Standard Deviation (SD) is used. It estimates the degree to which the group of scores deviates from the mean. The formula which is used to calculate SD is shown below: $S D=\sqrt{\frac{\sum d^{2}}{N}}$

$\mathrm{N}$ is the number of scores and $\mathrm{d}$ the deviation of each score from the mean. (ibid:170)

\section{Section Four}

\section{$\underline{\text { Analysis of Results }}$}

\subsection{Introduction}

This section deals with analyzing the results of test which have been carried out by college students in using and identifying some deictic expressions. The researcher has used different statistical methods as mentioned in section three to estimate whether there is a significant difference among the scores of the students in the test.

\subsection{Comparison of the Students' Scores in the Test:}

In order to determine whether there is a significant difference among the mean scores of the students in the test and its repetition, the researcher has compared the mean scores of the group of the students; the mean of the students in the first try of the test is (14.6), and the mean of the students in the second try is (13.96). The ' $t$ ' test for paired samples is calculated in order to estimate the significant difference among the mean scores of the students. The ' $\mathrm{t}$ ' value is (1.02), it is compared with the ' $\mathrm{t}$ ' critical value which is (2.000). This comparison indicated that there is no significant difference at .05 level among the scores of the students. So, the third hypothesis which is adopted initially is accepted. See Table (2)

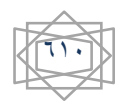



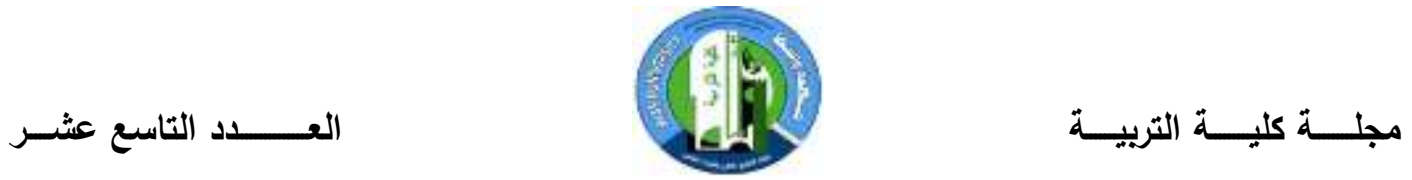

Table (2)

Mean, Standard Deviation and ' $\mathrm{t}$ ' Value of the Test Scores

\begin{tabular}{|c|c|c|c|c|}
\hline $\begin{array}{c}\text { No. of } \\
\text { Stuedents }\end{array}$ & Mean X & $\begin{array}{c}\text { Standard } \\
\text { Deviation } \\
\text { S.D. }\end{array}$ & $\begin{array}{c}\text { Degree of } \\
\text { Freedom }\end{array}$ & 't' Value \\
\hline \multirow{2}{*}{25} & $14.6\left(1^{\text {st }}\right)$ & 33.13 & 24 & 1.02 \\
\cline { 2 - 3 } & $13.96\left(2^{\text {nd }}\right)$ & 31.76 & & \\
\hline
\end{tabular}

\subsection{Analyzing the Students' Errors Related to Question One of the Test:}

The researcher has analyzed the whole test counting the student's correct and incorrect responses of the subject with their percentage. The discussion of the results has concentrated on incorrect responses, because the present study tackles the errors which have been made by the students. So, the first question of the test consists of (8) items with (20) deleted deictic words and phrases which have been distributed randomly on these items in the form of blanks with their types. 


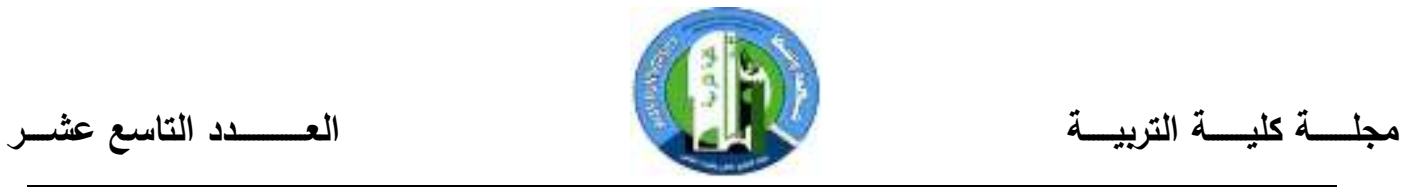

Table (3)

Analyzing the Results Related to Question One of the Test

\begin{tabular}{|c|c|c|c|c|c|c|c|c|c|}
\hline $\begin{array}{c}\text { No. } \\
\text { of } \\
\text { item }\end{array}$ & $\begin{array}{c}\text { Deictic Word or } \\
\text { phrase }\end{array}$ & $\begin{array}{c}\text { Corr. } \\
\text { answer }\end{array}$ & $\begin{array}{c}\text { Perc. } \\
\%\end{array}$ & $\begin{array}{c}\text { Its } \\
\text { type }\end{array}$ & $\begin{array}{c}\text { Perc. } \\
\%\end{array}$ & $\begin{array}{c}\text { Incorr. } \\
\text { answer }\end{array}$ & Perc. \% & $\begin{array}{c}\text { Its } \\
\text { type }\end{array}$ & Perc. \% \\
\hline $1-$ & Friends & 14 & 56 & 7 & 28 & 11 & 44 & 18 & 72 \\
& liegeman & 15 & 20 & zero & zero & 20 & 80 & 25 & 100 \\
\hline $2-$ & Thus & 3 & 12 & zero & 100 & 22 & 88 & 25 & 100 \\
& before & 12 & 48 & 11 & 44 & 13 & 52 & 14 & 56 \\
& this dead hour & 14 & 56 & 10 & 40 & 11 & 44 & 15 & 60 \\
& gone & 4 & 16 & 4 & 16 & 21 & 84 & 21 & 84 \\
& by our watch & 7 & 28 & 6 & 24 & 18 & 72 & 19 & 76 \\
\hline $3-$ & My lord & 15 & 60 & 2 & 8 & 10 & 40 & 13 & 52 \\
\hline $4-$ & Too long & 10 & 40 & 6 & 24 & 15 & 60 & 19 & 76 \\
& Comes & 10 & 40 & 8 & 32 & 15 & 60 & 17 & 68 \\
\hline $5-$ & Thou (you) & 10 & 40 & 8 & 32 & 15 & 60 & 17 & 68 \\
& Me & 9 & 36 & 9 & 36 & 16 & 64 & 16 & 64 \\
& Go & 7 & 28 & 8 & 32 & 18 & 72 & 17 & 68 \\
& Further & 4 & 16 & 4 & 16 & 21 & 84 & 21 & 84 \\
\hline $6-$ & Here & 11 & 44 & 11 & 44 & 14 & 56 & 14 & 56 \\
& And & 1 & 4 & 1 & 4 & 24 & 96 & 24 & 96 \\
& My son & 13 & 52 & zero & zero & 12 & 48 & 25 & 100 \\
\hline $7-$ & Sailors & 9 & 36 & 2 & 8 & 16 & 64 & 23 & 92 \\
& My lord & 16 & 64 & 7 & 28 & 9 & 36 & 18 & 72 \\
\hline $8-$ & Therefore & 2 & 8 & 2 & 8 & 23 & 92 & 23 & 92 \\
\hline
\end{tabular}

So , the results can be summarized as follows:

1. The deictic words in item number (1) are: friends and liegeman. The percentage of correct responses for (friends) is 56\%. While the percentage of incorrect responses is $44 \%$. Thus, the students can recognize and indicate this word correctly. The perc. of correct responses of its type is $28 \%$. While the perc. of incorrect responses of its type is $72 \%$. According to these percentages, it is noticed that the students can not distinguish and indicate the correct type because the students may be forgotten this subject which have been taken in the previous year (third year). For (liegeman) the perc. of incorrect responses is $80 \%$. The perc. of correct responses is $20 \%$. So, the students make many errors in stating this word. Also, the perc. of incorrect responses of its type is $100 \%$. While, the perc. of correct responses of its type is Zero\%. This result indicates that the students can not state its type correctly. 
2. In item (2): it is recognized that the percentages of correct answers are lower than the percentages of incorrect answers for the words (thus, gone and by our watch). This shows that the students have difficulties in indicating or using these words in their right place. Also, the percentages of incorrect answers of their types are higher than the percentages of correct answers of their types. This difficulty indicates that these words are ambiguous for the students because they belong to old language of the play of Hamlet. Besides, the perc. of correct answers for the word (before) is $48 \%$. While the perc. of incorrect answers is $52 \%$. The perc. of correct answers of its type is $44 \%$ and the perc. of incorrect answers of its type is $56 \%$. In addition, the perc. of correct answers for the phrase (this dead hour) is 56\%, and the perc. of incorrect answers is $44 \%$. Also, the perc. of incorrect answers of its type is $60 \%$ and the perc. of correct answers of its type is $40 \%$. According to these percentages, this indicates that the students have equal difficulty in recognizing these words or phrases and make the same errors.

3. The phrase (my lord) in item (3): the perc. of correct responses is (60\%) and the perc. of incorrect responses is $40 \%$. This illustrates that the students recognize the correct answer because it is common for the students and they have heard more. While, the perc. of incorrect answers of its type is $52 \%$, and the perc. of correct answers of its type is $8 \%$. This indicates that the students make many errors in recognizing the type of this phrase.

4. The words (too long) and (comes) in item (4): the percentages of correct answers are the same (40\%), and the percentages of incorrect answers also are the same (60\%). These percentages indicate that the same mistakes are made by the students and they fail in solving this item correctly. So, they have the same difficulty in recognizing the correct answer. While, the percentages of correct answers of their types are as follows (24\%) and (32\%) and the percentages of incorrect answers of their types are as follows (76\%) and (68\%). There are some similarity in these percentages, so that the students don't recognize the types of these deictic words in their correct use.

5. The words in item (5) are thou (you), me, go, further. The percentages of correct answers for these words as follows: $40 \%, 36 \%, 28 \%$ and $16 \%$. While the percentages of incorrect answers for these words as follows: $60 \%, 64 \%, 72 \%$ and $84 \%$. These different percentages indicate that the students make many errors and face many difficulties 


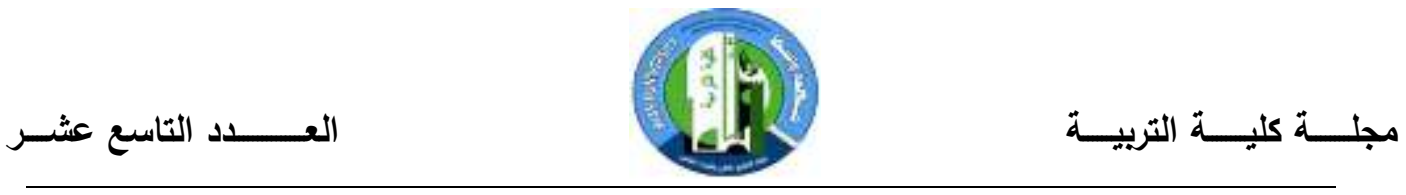

especially in the word "further", because it has the highest percentage from others. Also, the percentages of correct responses of their type can be mentioned as follows: $32 \%, 36 \%, 32 \%$ and $16 \%$. The words "thou" and "go" have the same percentages. So, this result indicates that the same students can recognize the correct answer of the words' types. Also, the percentages of incorrect responses for their type can be shown as follows: 68\%, 64\%, 68\% and 84\%. The words "thou" and "go" have the same percentages, so that the same number of students have made the same mistake in not recognizing the correct type.

6. In item (6): the phrase "my son" has the highest percentage of correct responses which is $52 \%$ than the other words like "here" and "and" which are as follows: $44 \%$ and $4 \%$ while for their type, the word "here" has the highest percentage which is $44 \%$ than the other words like "and" and "my son" which are as follows : 4\% and 0\%. For the percentages of incorrect responses for the words "here" and "and" and their type have the same percentages for both :56\% and 96\%. While, the percentage of incorrect answers for the phrase "my son" is $48 \%$ and the percentage of its type is $100 \%$. This result clarifies that no one of students can mention the correct type.

7. The percentages of correct answers and incorrect answers for the words "sailors" and "my lord" are vice versa which are as follows: $36 \%, 64 \%$ and $64 \%, 36 \%$. From these results can be understood that the same number of students can answer these words correctly and incorrectly. While the percentages of incorrect answers for their type are as follows $99 \%$ and $72 \%$ which are higher than the percentages of correct answers for their type which are as follows $8 \%$ and $28 \%$.

8. In the word "therefore" the percentages of correct answers with its type are the same $8 \%$ and $8 \%$. And the percentages of incorrect answers with its type also are the same $92 \%$ and $92 \%$. This result points to that the students have answered this item incorrectly larger than the correct answers.

\subsection{Analyzing the Students' Errors Related to Question two of the test:}

The answers of this question have been corrected and analyzed by the researcher. Question two consists of three items with (10) deleted deictic

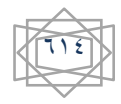


words and phrases in the form of blanks. So, the students are asked to fill the blank with appropriate word or phrase from their own in order to give the most suitable deictic word or phrase from the play of "Hamlet" which has been studied in the third class.

Table (4)

Analyzing the Results Related to Question Two of the Test

\begin{tabular}{|c|c|c|c|c|c|}
\hline $\begin{array}{c}\text { No. of } \\
\text { item }\end{array}$ & Deictic word or phrase (blank) & $\begin{array}{c}\text { Corr. } \\
\text { answer }\end{array}$ & Perc. \% & $\begin{array}{c}\text { Incorr. } \\
\text { answer }\end{array}$ & Perc. \% \\
\hline \multirow{4}{*}{1} & Thy (your) & 12 & 40 & 13 & 60 \\
& her & 11 & 48 & 14 & 52 \\
& us & Zero & Zero & 25 & 100 \\
\hline \multirow{2}{*}{2} & Wo & 1 & 4 & 24 & 96 \\
& Wittenberg & 1 & 4 & 24 & 96 \\
\hline \multirow{3}{*}{3} & Such times & 6 & 24 & 19 & 76 \\
\hline & Doubtful Phrases & 6 & 24 & 19 & 76 \\
& Gone & Zero & Zero & 25 & 100 \\
\hline
\end{tabular}

So, the results of this question have been analyzed in the form of percentages of correct and incorrect answers of the students which can be summarized as follows:

1. In item (1): the words "us" and "wittenberg" have the same percentages of incorrect answers which are $100 \%$ and 100\%. This result explains that no one of students has filled these blanks correctly. Thus, no one knows the correct answer. In addition, the percentage of incorrect answer for the word "go" is 26\%. And the percentage of correct answer is $4 \%$. Also, the percentages of incorrect answers for the words "thy which means (your)" and "her" are as follows: $60 \%$ and $52 \%$. While, the percentages of correct answer are as follows: $40 \%$ and $48 \%$. The percentages of incorrect answer in this item are higher than the percentages of correct answer. Therefore, the sample of students in this study can not produce the correct answer and they make many errors in this item because they don't know and use the correct deictic word which can fill the blank.

2. The percentages of correct answers for the phrases "such times" and " doubtful phrases" in item (2) are 4\% and 24\%. While the percentages of incorrect answers for these phrases are as follows: $96 \%$ and $76 \%$. So, the percentages of incorrect answers for these phrases are higher 

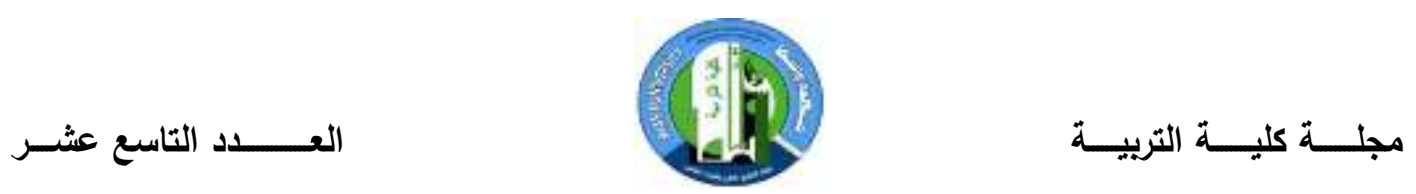

than the percentages of correct answers. These percentages indicate that the students have failed in answering these blanks correctly. This may be caused by the students that couldn't produce the correct suitable deictic words or phrases which related to the play of "Hamlet".

3. In item (3), the word "lady" has $0 \%$ zero percentage of correct answers. Thus, the percentage of incorrect answers is $100 \%$. This emphasizes that no one of students can recognize the correct answer. Also, the percentage of incorrect answers for the phrase "At his heads" is $96 \%$ while the percentage of correct answers is $4 \%$. The percentage of correct answers for the word "Gone" is $24 \%$ and the percentage of incorrect answers is $76 \%$. These results indicate that the students have faced many problems in this subject and they couldn't recognize and produce the suitable deictic words or phrases. So, they commit many errors in this matter. These problems due to the weakness of the students in the subject of deixis especially in the deictic expressions. In addition, the students may be forgotten this subject and how to use it correctly especially in writing and in drama. Because the play of Shakespeare "Hamlet" has a large number of deictic words and phrases. So, the students have mixed among these expressions. Hypothesis number (1) and (2) can be achieved and clarified. 


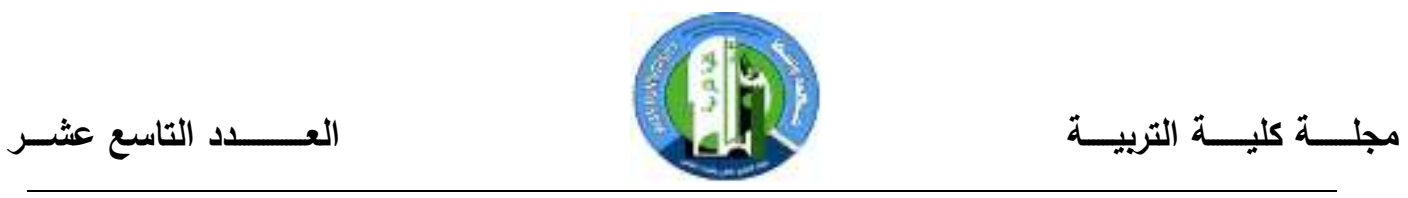

Section Five

\section{Conclusions}

This section introduces the main conclusions that have been reached by the researcher:

Deixis is one of the most important notions in general linguistics. So, deictic expressions depend primarily on features of the context involved such as the speaker and hearer, their location in space and time, etc.

Also, deictic expressions function to activate specific shared knowledge and the use of deictic expressions is different from one person to another according to his culture and age.

Therefore, the types of deictic interfere differently. Firstly, there is a complete interference between the social and the personal types as in the case of madam, king, and mother. Also, another complete interference is found between the personal and the spatial types as in the word "Norway" which is used to refer to the state and to the king. A less degree of interference is clear in the use of the adverbs "after" and "before" in both the spatial and the temporal types. And the least degree of interference is indicated by the use of the definite article and the demonstratives in all the five types.

In addition to that, drama is a main domain for deixis because it contains a large number of deictic examples as "I", here and, now. So, the play of Shakespeare's "Hamlet" is used by the researcher in this study as an example for deictic expressions. Thus, from the analysis of the results of the test, the researcher has indicated that the students cannot distinguish among the various types of deixis and how they can be used correctly especially in the situation. So, the students have faced many difficulties and problems in not recognizing the correct deictic word and its type. Hence, they commit many errors in this subject. In order to avoid this problem the researcher suggests that the teachers of English language should learn and train their students more about the subject of deixis and how they can use and understand deictic expressions to reflect the theme of the play. Drama is considered as a main domain of deixis, so that the teachers of literature should concentrate on this subject in their teaching for different types of plays for many writers because it is very important term in linguistics and in literature. 